Portland State University

PDXScholar

\title{
Lessons Learned from the Implementation of a Medically Enhanced Residential Treatment (Mert) Model Integrating Intravenous Antibiotics and Residential Addiction Treatment
}

\author{
Talitha Wilson \\ Oregon Health \& Science University \\ Devin Collins \\ Oregon Health \& Science University \\ Elena Phoutrides \\ Oregon Health \& Science University \\ Melissa B. Weimer \\ Oregon Health \& Science University \\ Followd Khorthuis \\ Oregon Health \& Science University \\ Part of the Infectious Disease Commons, and the Substance Abuse and Addiction Commons \\ see next page for additional authors
}

\section{Citation Details}

Englander, Honora, Talitha Wilson, Devin Collins, Elena Phoutrides, Melissa Weimer, P. Todd Korthuis, Jessica Calcagni, and Christina Nicolaidis. "Lessons learned from the implementation of a medically enhanced residential treatment (MERT) model integrating intravenous antibiotics and residential addiction treatment." Substance abuse just-accepted (2018): 1-25.

This Post-Print is brought to you for free and open access. It has been accepted for inclusion in Social Work Faculty Publications and Presentations by an authorized administrator of PDXScholar. Please contact us if we can make this document more accessible: pdxscholar@pdx.edu. 


\section{Authors}

Talitha Wilson, Devin Collins, Elena Phoutrides, Melissa B. Weimer, P. Todd Korthuis, Jessica Calcagni, and Christina Nicolaidis 
Publisher: Taylor \& Francis

Journal: Substance Abuse

DOI: https://doi.org/10.1080/08897077.2018.1452326

Lessons learned from the implementation of a medically enhanced residential treatment (MERT) model integrating intravenous antibiotics and residentiai adiction treatment Honora Englander, $\mathrm{MD}^{1,2}$

Talitha Wilson ${ }^{1}$

Devin Collins, $\mathrm{MA}^{1}$

Elena Phoutrides, MD, $\mathrm{MPH}^{1}$

Melissa Weimer, DO, MCR

P. Todd Korthuis $\mathrm{MS}, \mathrm{MPH}^{1}$

Jessica Calcagiil CADC I, MA ${ }^{4}$

Christina Nicolaidis, MD, MPH ${ }^{1,5}$

1. Oregon Health \& Science University, Portland, OR

2. Cental City Concern, Portland, OR

3. St. Peters Health Partners, Albany, NY

4. CODA, Inc., Portland, OR

5. Portland State University School of Social Work, Portland, OR

Corresponding author: 
Honora Englander, MD, FACP

BTE 119, Oregon Health \& Science University

3181 SW Sam Jackson Park Road

Portland, Oregon 97239

Phone 503-494-8311

englandh@ohsu.edu

Acknowledgements: Authors would like to thank Claire Dorfman, Alison Nvice, Luke Strnad, Tara Williams, and Catherine Maria Michalczyk for their support of this work. Authors would also like to acknowledge Daren Ford, Onesha Cochran, Leif Otterbecher, Lisa Rivers, Pen Barnes, and the entire IMPACT clinical team. Dr. Korthuis' time was supported through grants from the NIH National Institute on Drug Abuse (UG3DA044831, U10DA015815). This publication was made possible with support from the Oregon Clinical and Translational Research Institute (OCTRI), grant number J LTRR024140 01 from the National Center for Research Resources (NCRR), a comporent of the National Institutes of Health (NIH), and NIH Roadmap for Medical Research

Funding: JISU and CareOregon funded this work. The funding organization had no role in the design and condyct of the study; collection, management, analysis, and interpretation of the data; preparation, review, or approval of the manuscript; and decision to submit the manuscript for puvilication. 
Author Contributions: Dr Englander was involved in conception and design, data analysis, interpretation of the results, writing and revision of the manuscript. Ms Wilson and Mr Collins were involved in data collection, analysis, interpretation of the results, and writing and revision of the manuscript. Dr Phoutrides was involved in conception and design and revision of the manuscript. Dr Weimer was involved in conception and design, analysis, interpretation of the results, and writing the manuscript. Dr Korthuis was involved in conception and design, aniaiysis, and revising the manuscript. Ms Calcagni was involved in analysis, interpreation of the results, and revision of the manuscript. Dr Nicolaidis was involved in conception and lesign, analysis, interpretation of the results, writing and revision of the manuscript.

Conflict of Interest: No authors have any conflicts of interest io disclose

Word Count: Manuscript 3602; Abstract 300

Exhibits: 1 figure, 2 tables, 1 appendix

\begin{abstract}
BACKGROUND: Hospitalizations for severe infections associated with substance use disorder (SUD) are increasing. Pesple with SUD often remain hospitalized for many weeks instead of completing intravenous antibiotics at home; often, they are denied skilled nursing facility adrniosior. Residential SUD treatment facilities are not equipped to administer intravenous antibiotics. We developed a medically enhanced residential treatment (MERT) medel integrating residential SUD treatment and long-term IV antibiotics as part of a broader hospital-based addiction medicine service. MERT had low recruitment and retention, and ended after six months. The goal of this study was to describe the feasibility and acceptability of MERT, to understand implementation factors, and explore lessons learned.
\end{abstract}


METHODS: We conducted a mixed-methods evaluation. We included all potentially eligible MERT patients, defined by those needing $\geq 2$ weeks of intravenous antibiotics discharged from February 1 to August 1,2016. We used chart review to identify diagnoses, antibiotic treatmiert location, and number of recommended and actual IV antibiotic-days completed. We audiorecorded and transcribed key informant interviews with patients and staff. We conducted an ethnographic analysis of interview transcripts and implementation field notes.

RESULTS: Of the 45 patients needing long-term intravenous antibiotics 18 were ineligible and 20 declined MERT. 7 enrolled in MERT and three compieted their recommended intravenous antibiotic course. MERT recruitment barriers included patient ambivalence towards residential treatment, wanting to prioritize physical health needs, ard fears of untreated pain in residential. MERT retention barriers included high demands of residential treatment, restrictive practices due to PICC lines, and perceptions by staff and other residents that MERT patients "stood out" as "different." Despite the chalienges, key informants felt MERT was a positive construct.

CONCLUSIONS. Though NiERT had many possible advantages; it proved more challenging to implement than anticinated. Our lessons may be applicable to future models integrating posthospitai intravenous antibiotics and SUD care.

\section{Introduction:}


United States hospitalizations for severe infections such as endocarditis and osteomyelitis among people with substance use disorder (SUD) have doubled in the last decade. ${ }^{1}$ Treatment for such infections typically requires six to eight weeks of intravenous (IV) antibiotics, and may require heart-valve surgery or other invasive procedures.

Many people can complete a prolonged course of IV antibiotics at home or in a postacute care skilled nursing facility (SNF). However, people with SUD are often deemed unsafe to discharge home with IV antibiotics because of social risks such as homejessness or continued drug use; and often, they are denied admission to post-acute care facilities. ${ }^{2.3}$ Thus, many with SUD have hospitalizations that extend weeks or months to complete an antibiotic course. ${ }^{4}$

Despite this, outcomes remain poor. People with SUD are more likely to be denied valve surgery, leave the hospital against medical advice, and cie. ${ }^{2,5}$ Hospital systems commonly do not provide SUD treatment, yet hospitalization can be a reachable moment to initiate and coordinate SUD treatment. ${ }^{6}$

Just as hospitals are not equipped to provide SUD treatment, SUD treatment settings are not equipped to provide complex medical care. ${ }^{4}$ Residential addiction treatment settings are not routinely staffed by physicians or nurses and do not have expertise to provide wound care, intravenous antibiotics, or other physical health care.

Stuclies examining alternative care models to address combined antibiotic and SUD needs are limited. One single-site, retrospective study retrospectively reviewed 205 medical charts of patients discharged to a residential addiction treatment setting where they received IV antibiotics between 2006 and $2011 .{ }^{7}$ Seventy-three percent of patients completed their course of antibiotics, with sizable savings in hospital days and costs. However, this study did not report patient 
characteristics, preferences, or outcomes of those who did not enter this care model. This study did not describe patient or SUD treatment provider experiences, nor did it describe implementation experience.

We developed and implemented a medically enhanced residential treatment (MERT) model as part of a broader hospital-based addiction medicine service ${ }^{4}$. MERT aimed to deliver IV antibiotics in residential addiction treatment for patients with SUD who were rnedically stable for discharge but needed ongoing long-term IV antibiotics. While the overall hospital-based addiction medicine service thrived, MERT had low recruitment and retention. Ultimately we decided to end MERT after six months. The goal of this study was to describe the feasibility and acceptability of MERT; and, given limited acceptability, to inderstand implementation barriers and explore lessons learned.

\section{Methods}

MERT was part of a nuiticemponent hospital-based addiction medicine intervention, the Improving Addiction Care Team (I.MACT) that includes care from addiction medicine physicians, social workers, and peers with lived experience in recovery. All MERT patients received care from IMPACT. Earlier studies describe IMPACT rationale and design. ${ }^{4,6}$ Our institutional reviey board approved all study procedures. Setitivg.

MERT was a collaboration between a university hospital, a community-based SUD treatment agency, and a specialty infusion pharmacy. The hospital is a 522-bed urban academic medical center in Oregon. During the study period, the hospital had an Outpatient Parenteral Antibiotic Therapy (OPAT) program. OPAT managed all patients leaving the hospital with 
intravenous antibiotics and included direct medical care from infectious disease providers and intensive case management. OPAT monitored antibiotic complications, completion, and follow up needs (e.g. laboratory tests).

The community-based SUD treatment agency (CODA) is a non-profit agency that provides outpatient treatment, medication for addiction treatment (MAT) (e.g. methadone, buprenorphine), medically supervised withdrawal, and residential treatment. The residentral site that housed MERT includes 42 men's beds and 22 women's beds. Prior to MERT, residential treatment did not have nursing or medical staff. Residential treatment enforced the traditional 30day "blackout period" during which unsupervised visitors, peronal mobile devices, and internet use is prohibited. CODA agreed to prioritize MERT patients waiting for a residential bed.

The specialty infusion pharmacy is a private company whose nurses deliver home infusion services including antibiotic administration and real-time support in the case of complications (e.g. catheter malfunction). The company had not previously worked in residential treatment.

Intervention Description:

MERT was located within a traditional residential addiction treatment setting where residents were expected to participate in 20 hours of groups and 1 hour of individual therapy each week. Forne infusion nurses administered daily antibiotic infusions and performed weekly dressing changes of peripherally inserted central catheters (PICC). The MERT registered nurse (RN) did an in-person handoff with hospital nurses and IMPACT prior to discharge and accompanied patients directly from hospital to MERT. All team members were informed of the workflow (appendix). The MERT RN coordinated post-hospital medical care and attended all off-campus follow-up visits. MERT patients and MERT RN participated in weekly telemedicine 
rounds with the hospital-based infectious disease team. We made establishing with a primary care provider (and in some cases a mental health provider) a requirement for MERT.

Hospital-based infectious disease teams referred all patients needing long-term IV antibiotics (defined as $\geq 2$ weeks) with SUD to IMPACT, and all were considered for MERT. MERT patients had to agree to enroll in residential SUD treatment; meet residential treatment criteria based on addiction severity (ASAM level of care 3.1-3.5); perform acivities of daily living independently; require no more than once daily antibiotic infusions; irmit prescription opioids for pain to no more than three times daily with a taper plan; and, have insurance that would cover residential addiction treatment at CODA.

During hospitalization, an IMPACT social worker assessed all potential MERT patients' interest in MERT and worked to enhance treatment motivation. The MERT registered nurse (RN) visited all interested patients in their hospital roctn to discuss treatment expectations and to review the anticipated residential care plan.

\section{Intervention Financing}

MERT was funded hy Oregor Health \& Science University and a Medicaid coordinated care organization. W We esimated that MERT would serve approximately 30 patients/year and 3 indiviauals at any time. We contracted to pay infusion pharmacy for 6-days/ week of infusion costs (insurance covers once-weekly home infusion) and we supported additional CODA resideritial staffing that included 0.1 physician, $0.7 \mathrm{RN}, 0.2$ residential manager time. ${ }^{4}$ The hospital infectious disease OPAT team provided in-kind support for 30 minutes/week telehealth rounds. 


\section{Implementation Process}

We constructed stakeholder partnerships that were integral to the design, ${ }^{4}$ implementation, and evaluation phases of MERT. We held on-site planning visits at the hospital and residential settings that included all partners. During implementation we held biweekly meetings with IMPACT clinicians and residential staff to identify potentially eligible patients and diseuss barriers and potential solutions. As we identified barriers (e.g. residential staff discomfort with wound care), we provided staff trainings to address them. We also modified the intervention to better serve complex patient-care needs. For example, IMPACT helped patients change insurance and tailored antibiotics to once daily regimens if possible. In one case, IMPACT worked with federal marshals and local parole officers to squash varrants to avoid incarceration and permit entrance into residential. We held quarterly mieetings with all partners across organizations and roles (e.g. clinical care, implenentation, evaluation).

\section{Evaluation}

We conducted a mixed-methods evaluation of MERT implementation. We employed a sequential explanatory research design, ${ }^{8}$ using qualitative data to gain a deeper understanding of quantitative results Our evaluation included all IMPACT patients who were potentially eligible for MERT, as disfined by those needing at least 2 weeks of IV antibiotics who were discharged bctiveen February 1 and August 1, 2016.

\section{Quantitative data collection and analysis}

We collected demographic data including age, gender, race, and insurance from hospital administrative data. We collected data on housing and substance use from an IMPACT study 
registry. We performed chart review to identify primary hospital diagnosis, antibiotic treatment location (MERT, hospital, SNF, home); number of recommended IV antibiotic days and actual IV antibiotic days completed. We used a study registry to identify reasons people did not attempt MERT and confirmed reasons by chart review.

We defined antibiotic completion if the actual number of treatment days was greater than or equal to the number of days of IV antibiotics recommended. We considered salvage therapy if patients transitioned to oral therapy prior to completing the recommended IV antibio ic course. We considered therapy incomplete if participants completed neither IV antiviotics nor salvage therapy.

Qualitative data collection and analysis

We performed semi-structured intervievs with key informants to understand barriers, facilitators, and effects of MERT. We also reviewed MERT development and implementation field notes. We used purposive sampling to identify six key informants including: an IMPACT social worker, the CODA-IMPACT iiaison, an IMPACT physician, CODA's executive director, the residential manager, and the MERT RN. We conducted qualitative interviews with four patients who needed jong-term IV antibiotics, two who went to MERT and two who did not. Patient parcicipants completed interviews approximately 30 days after hospital discharge.

All interviews were audio recorded and transcribed. We conducted an ethnographic anailysis of interview transcripts and field notes, focusing on insights that may best describe the phenomenon and inform future interventions. ${ }^{9}$ Two authors independently coded all transcripts and reconciled codes by consensus. We reviewed preliminary findings with key informants as a 
form of member checking. The full team, including experts in qualitative methods and SUD, finalized results.

\section{Results:}

\section{Recruitment}

During the study period there were 45 patients needing long-term IV antibiotics (Table 1). Eighteen were ineligible, 20 declined, and 7 discharged to MERT. Pătients were ineligible for various reasons, including active warrants, insurance, need for multiple daily antibiotic infusions, inability to perform independent activities of daily living, ongoing physical rehabilitation needs. Most patients who declined were unwilling to commit to residential treatment (Figure 1).

Key informants repeatedly described that MER'I was "hard to sell." Many patients expressed ambivalence towards residential treatnent, especially after acute hospitalization. As an IMPACT physician recalled:

"Many patients woula say, I want to address my medical issues now and then I'll address my addiction issues after... we heard [that] over and over."

For some, arnbivalence was exacerbated by a changing medical plan and discharge date, which made coordinating a residential bed difficult. Facing so many "what-if”s," some patients' motivation waned. Some had concerns about the demands of a highly structured treatment program and others did not want to be separated from friends, family, pets and home. 
Patients also worried about getting adequate pain control in residential, and feared that by agreeing to MERT, they would have to forgo pain medication. As one patient who attended MERT recalled,

"Having my surgery on my back, and then 10 days later, "let's stick you in a treatment facility"... where I had to walk around and take classes.... I was initially worried about my physical ability to do so.... I was gonna be in a significant amount of pair... [and] the transition from my oxycodone and dilaudid to methadone conceined ine at first..."

\section{Retention:}

Of the 7 patients who went to MERT, 4 left against medical advice (AMA) before completing the recommended antibiotic course. Key informants highlighted "culture shock" with the transition from the hospital to MERT They repeatedly described that the 20-hours of per week of groups was challenging for MERT patients. As MERT's residential manager described:

"Patients were in the hospital for long periods of time, so there was a lot of downtime... and once they got into treatment... you're talking about a pretty strict schedule. They were expected to get up at a certain time, your meal is at a certain time, you have to go take you medications. And you have to do that as opposed to a nurse getting everything to you, and I can watch TV and sleep in... it is a different mindset that you really had to be ready for."

In some cases, staff perceived MERT patients' lesser participation in residential as disruptive to the treatment environment. 
Attitudes of residential staff towards medical complexity may have influenced retention. An IMPACT social worker recalled his sense that, "[some] counselors were refusing to work with the MERT patients... because of the medical complexities. Not because they didn't like them or want them, but because they were hard, difficult, complex people." Residential staff often felt "on edge" because patients had PICC lines, which they feared were "a direct portai right to their heart, they could overdose at any moment." These fears increased staifs vigilance and led them to implement added restrictions for MERT patients. As the res dentia) program manager described:

"[Staff] couldn't let them out into the community. We conldn't let them ... be outside and do exercise walks, or those kinds of things because it was really high risk... It's hard to watch your peers be able to come and go in the community, and you not be able to participate."

These restrictions were repeatedly identified as a key barrier to MERT completion rates, and led to MERT patient dissatisfaction. As one patient described, MERT felt "like jail" and he felt “completely lied to." IMPACT ieadership, inpatient addiction medicine, and infectious disease teams only learned about these restrictions after MERT had ended.

Finaly, key informants described that MERT patients were often "isolated" from other residents. They speculated that this resulted partly from fear of contagion given visible wounds, stigma tervards those with medical illness, resentment of "special treatment" that allowed MERT patierits to be accompanied to off-campus medical appointments, and use of MAT that was uncommon amongst other residents. The IMPACT-CODA liaison described: 
"A lot of the patients at residential sort of pushed against that. The IMPACT patients, like, you just sort of got here. And you took someone else's bed... you don't have to go to groups because you have to go to an appointment. Or just like, you get specialized care. And that just really rubbed against patients the wrong way."

\section{Potential Utility:}

Though overall IV antibiotic completion was low (44\%), a majority of participants either completed $\geq 80 \%$ of recommended IV antibiotics (64\%) and/or completed saivage therapy (24\%). A combination of discharge to MERT, SNF, or home allowed for 384 days of IV antibiotics delivered outside of the hospital. Though numbers are too small for statistical comparisons, information about antibiotic completion rates and out-of-hospital IV antibiotic days are presented in table 2.

Despite the challenges, neariv ali respondents felt that the MERT construct was positive and worth pursuing again. Respondents felt that the patients who completed MERT benefitted greatly. As the MERT RNYemphasized, "there wasn't anything else like it ... the people it did impact, it profoundly impacted." Respondents praised MERT's success with highly motivated patients, parícularly those with external motivating factors such as reuniting with their family or avoiding legal issues.

This sentimient was echoed by one patient who completed the program:

"I'm so grateful for this program cause instead of being in the hospital... and just basically doing nothing except getting your injection every day... out here, not only do I get to address my addiction, but I have the opportunity to go to NA meetings or AA 
meetings... Initially, I probably went into the program saying 'hey, well I'll just wait for my antibiotics to be done and then I can leave.' Well, no. After a couple a days, I'm like that's not what I really want. I want to finish this program. I need to do things differently."

Finally, independent of MERT's explicit goal to facilitate access to IV antibiscics. respondents noted that having an on-site nursing increased residential treatment's ability to care for more medically complex patients, including expanded use of MAT in residential (which he estimated "almost doubled") and more staff familiarity caring for patients with wounds, diabetes, or other common medical problems.

\section{MERT alternatives}

The majority of participants did not go to MERT, and instead went to SNF or stayed in the hospital. However, these settings had different limitations. SNFs commonly resisted accepting patients with SUD or homelessness, and SNFs felt they had limited ability to administer methadone due to their interpietation of federal regulations. SNF staff typically had no addiction training and the SNF environment was largely unmonitored with reports of active drug use on premises. Many S NF patients also felt ostracized due to their SUD. Hospital was a more controlled erivircnmert; however prolonged admissions are extremely costly. Furthermore, even with IMPACT, hospital care had limited ability to prepare patients for post-hospital trigger-rich Environments. As one staff participant described: "Just leaving the hospital... as soon as you drive down Burnside [street], you're in a more trigger rich environment. And you begin to lose people."

\section{Discussion:}


Though MERT had many possible theoretical advantages, it proved more challenging to implement than anticipated. Recruitment barriers included patient's medical complexity, patient concerns about physical health and pain, and ambivalence towards residential treatment.

Retention barriers included high demands of residential treatment, restrictive residential practices due to PICC lines, and the perception that MERT patients "stood out" as "different." Wespite the challenges, the majority of patients completed IV antibiotic or salvage therapy and NERT saved a modest number of hospital days. Most providers felt that there was some value in the care model that should inform future trial.

Our experience builds on existing research in severa: important ways. An earlier study by Jewell and colleagues ${ }^{7}$ describes a program that cont:nued successfully for 6 years with higher retention rates (73\% completing IV antibiotics versus our 43\%) and relatively low patient-volumes (<3 patients/ month). While an important precedent, Jewell and colleagues do not describe recruitment - describing experiences only of those who went to their program - nor do they elaborate on patient'staff experience. Our finding that many patients did not want residential treatment serves as an important caution that programs such as Jewell's may not be a solution for many patients and health systems.

Dj:ferences in the Jewell program and ours highlight potentially important differences in sctitings and implementation strategies. Higher retention rates in Jewell could be related to preexisting on-site nursing staff in residential treatment, which may have increased residential staffs' comfort managing medical problems and mitigated the perception that patients with medical illness were 'different.' Also, Jewell included a fixed monthly rate to reserve residential bed-capacity and an additional payment for each day a bed was occupied. In MERT, additional 
staff were financed up-front and were an expense even if there were no MERT patients. A daily rate may have incentivized residential staff to retain patients in residential and reduced financial strain on the hospital in that the hospital would pay for a resource proportional to its use. Importantly, the Jewell program was implemented in a more integrated system. The effort necessary to initiate and maintain MERT in non-integrated systems may be substantially greater. Finally, the challenges we had with patients who discharged to SNF echo others' descriptiont of post-acute barriers for patients with SUD in SNF. ${ }^{10}$

Our experience designing and implementing IMPACT supports that hospitalization is a reachable moment to engage patients and initiate addiction care. ${ }^{6}$ Howerer, residential treatment may represent a higher bar, particularly given the intensive residential addiction treatment demands; the restrictions on visitors, cell phones and internet, and limitations on opioid pain medications. Fear of unmet pain needs is a common concern amongst hospitalized patients with SUD. ${ }^{11}$ Others have questioned whether such restrictions are necessary. ${ }^{12}$ Our experience suggests that these barriers may dissuade patients from entering or completing residential treatment.

Our study has several key limitations. First, it took place at a single-academic medical center and single residential treatment program in Oregon, limiting the generalizability of our findings. Dur six-mionth experience included a small number of participants. Though we did not have large erough numbers to compare outcomes across various settings, we present outcomes for patients who remained inpatient or discharged to MERT, SNF, and home. Our qualitative evaluation focused on MERT and was not designed to thoroughly explore other treatment settings, a topic of future investigation. Despite these limitations, our experience may be important to others trying to improve care for people requiring intravenous antibiotics with SUD. 
Our experience has several key implications. The finding that hospitalized patients declined residential treatment is important and suggests the need for flexible, patient-centered post-acute care models that can engage patients who range from pre-contemplative to action stages of change. Findings that residential staff felt "on edge" and that patients with medical problems "stood out" in residential treatment underscore the need for training to support integrated physical and behavioral health models. Though we hired an on-site MERT narse and part-time physician who led some training, we underestimated the time and suppor residential staff would need to feel comfortable working with recently hospitalized pations. Future efforts might benefit from more dedicated time and resources for staff education, including all-staff trainings about PICC lines, MAT, and pain. Finally, though MERT was developed based on a patient needs assessment and broad stakeholder input $t^{4}$ our experience raises the question of whether a more iterative design process that included ongoing feedback from adults with SUD and residential staff may have led to a more successful intervention. Our experience highlights the need to anticipate and adapt to barriers relating to patients with SUD (e.g. concerns about pain management), organizations re.g changing hospital discharge dates and residential bed capacity), and the program itseif (e.g. staff attitudes).

Despite our challenges, we believe there may still be benefit to creating options for patients to receive ing-term IV antibiotics outside of the hospital. Even with low recruitment and retention we saved over 300 hospital days with the majority of patients completing IV antibictics or salvage therapy. Our findings underscore the need for more flexible, patientcentered treatment models. Future programs might integrate addiction supports into post-acute medical care. Given high prevalence of homelessness among people with SUD, a model that warrants exploration is to integrate IV antibiotics and substance use treatment in medical respite 
facilities. ${ }^{13}$ Medical respite - which is proliferating across the US - provides post-acute medical care for homeless persons who are too ill to recover from a physical illness on the streets. ${ }^{14}$ Medical respite could be staffed with nurses to provide infusions and case management; physicians to prescribe opioid agonist therapy; and, recovery supports, including peers in recovery. Alternatively, studies might explore modifying physical health treatment plans to accommodate patients' behavioral health needs, for example, exploring off-label once weekity antibiotic infusions for patients who decline SNF or threaten to leave the hospital AMA.

Future implementation research should explore alternative modeis of iritegrated treatment for patients with SUD requiring long-term intravenous antibiotics. It is unlikely that a single solution will emerge, especially given variations in settings and resources across communities. However, the lessons of our experience, including patient ambivalence towards residential treatment and the challenges of delivering physical healthcare in a residential addiction setting, are likely to be applicable in future models.

Appendix 
MERT DISCHARGE: Hospital $\rightarrow$ Residential Work Flow

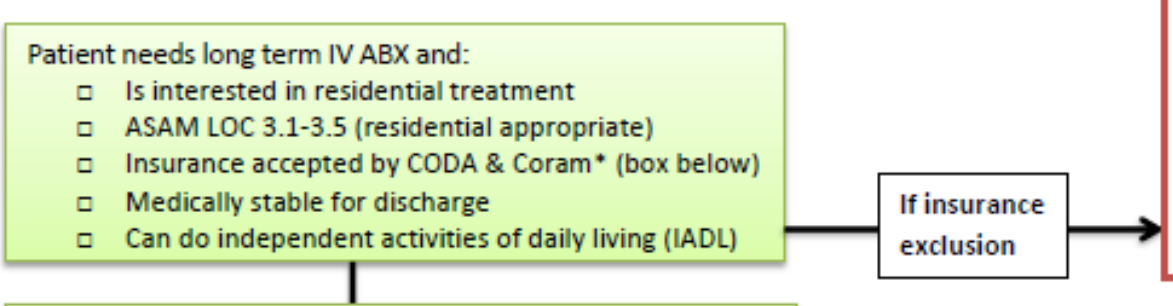

If insurance exclusion, alert IMPACT Director and may explore alternate payment options; may need extra

a CODA physician/in-reach confirm labs complete (RPR, LFTs, PPD), med plan enacted, screen for isolation precautions, residential appropriate

$\square$ Case Manager confirms PCP assignment

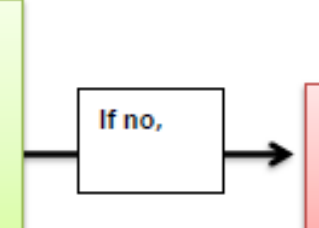
Care Mgr support re certair CCO prior authorization

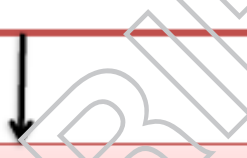

Case manager wnrks with IMPACT to identify aite.rnate DC, plar. (SNF) if possible

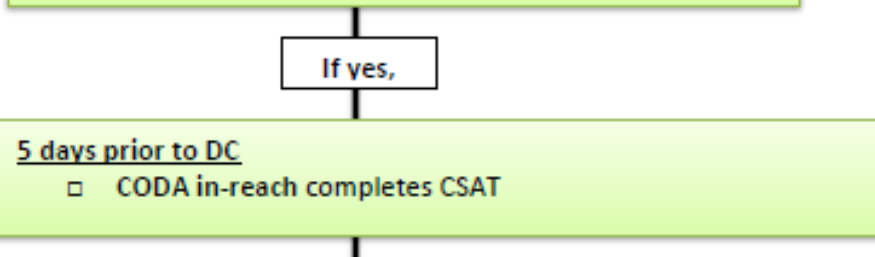

\section{$48 \mathrm{~h}$ prior to $\mathrm{DC}$}

CODA physician completes MAT order

口 OPAT confirms once daily ABX plan

ㅁ Case Manager alerts Coram with anticipated DC dats

口 Discharging MD:

口 Confirms PICC line in place

- Arranges wound care supplies

- IMPACT SW

口 Arranges clothing

․ coordinates specific time for irans,poitation

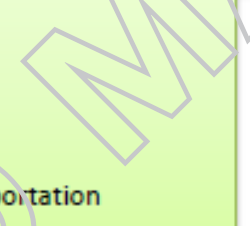

$\downarrow$

$48 \mathrm{~h}$ prior to $\mathrm{DC}$, communicate tise following, $\mathrm{LC}$ activities for $\mathrm{DC}$ day:

- Discharging MD sends prescription fo: 30 days meds to Pavilion pharmacy (except only $?$ days c f controlled substances; no methadone or sutoxorie)

口 Discharging ' $M D$ - cor pletes Di summary on day of DC

口 OPAT writes : $V$ A.BX order, surveillance labs, and contingency plan t'lat ok to pull PICC if pt leaves CODA AMA

- Unit rharinscist or RN picks up prescriptions at Pavilion

DC Date

- MERT RN accompanies patient to MERT via cab

L7 Ward RN confirm that patient has 1) meds and 2) DC summary to bring in hand to CODA
*Insurance Exclusions: bolded are most common exclusions Coram

- United healthcare

- Workers comp

- Atrio

- Melino (WA)

- Family care doesn't do any retro authorizations so we will have to anticipate this and work with their staff in advance

CODA

- Medicare (some county funds may be exception)

- Washington Medicaid

- Workers comp 
References:

1. Ronan MV and Herzig SJ. Hospitalizations Related To Opioid Abuse/Dependence And Associated Serious Infections Increased Sharply, 2002-12. Health Aff (Millwood). 2016;35(5):832-837.

2. Fanucchi L and Lofwall MR. Putting Parity into Practice - Integrating Opioid Use Disorder Treatment into the Hospital Setting. N Engl J Med. 2016;375(9);81 i-813.

3. Feigal J, Park B, Bramante C, Nordgaard C, Menk J and Song J. Homelessness and discharge delays from an urban safety net hospital. Public ifealth. 201/;128(11):10331035.

4. Englander H, Weimer M, Solotaroff R, et al. Planning and Designing the Improving Addiction Care Team (IMPACT) for Hospitalized Aaults with Substance Use Disorder. $J$ Hosp Med. 2017;12(5):339-342.

5. Slater MS, Komanapalli CB, Tripathy U, Ravichandran PS and Ungerleider RM. Treatment of endocarditis: a decade of experience. Ann Thorac Surg. 2007;83(6):20742079; discussion 2079-2080.

6. Velez CM, Nicolàidis C, Korthuis PT and Englander H. "It's been an Experience, a Life Learning Experience": A Qualitative Study of Hospitalized Patients with Substance Use Disoruers. J Gen Intern Med. 2017;32(3):296-303.

7. Jewell C, Weaver M, Sgroi C, Anderson K and Sayeed Z. Residential addiction treatment for injection drug users requiring intravenous antibiotics: a cost-reduction strategy. $J$ Addict Med. 2013;7(4):271-276.

8. Ivankova NV, Creswell JW and Stick SL. Using Mixed-Methods Sequential Explanatory Design: From Theory to Practice. Field Methods. 2006;18(1):3-20. 
9. Goodson L and Vassar M. An overview of ethnography in healthcare and medical education research. J Educ Eval Health Prof. 2011;8:4.

10. Wakeman SE and Rich JD. Barriers to Post-Acute Care for Patients on Opioid Agonist Therapy; An Example of Systematic Stigmatization of Addiction. J Gen Intern Med. 2017;32(1):17-19.

11. Merrill JO, Rhodes LA, Deyo RA, Marlatt GA and Bradley KA. Mutual mistrust in the medical care of drug users: the keys to the "narc" cabinet. J Gen Interr Mea. 2002;17(5):327-333.

12. Collier S and Gavriel M. Mobile phones in residential treatment: implications for practice. J Subst Abuse Treat. 2015;55:45-51.

13. Beieler AM, Dellit TH, Chan JD, et al. Successtur implementation of outpatient parenteral antimicrobial therapy at a medical respite facility for homeless patients. $J$ Hosp Med. 2016;11(8):531-535.

14. Zerger S, Doblin B and Thompson L. Medical respite care for homeless people: a growing national phenomienon. Health Care Poor Underserved. 2009;20(1):36-41.

15. Kathol RG, Butler M, McAlpine DD and Kane RL. Barriers to physical and mental condition jitegrated service delivery. Psychosom Med. 2010;72(6):511-518. 
Figure. Participant flow diagram.

Patients needing long-term IV antibiotics seen by IMPACT and discharged 2/1-8/1/2016

$(n=45)$

- A'nA frum hospital (6) or death (1) prior (o MírRT Hecision

- Medival anm plexity

o Need fror physical therapy/nursing (3)

- Multiple antibiotic doses per day (3)

- Irsurance barrier (2)

- Active warrant (2)

- Disruptive with staff (1)

Declined MERT $(n=20)$

- Unvilling to commit to residential treatment (13)

- Separation from friends/family (6)

- Patient antibiotic therapy concerns (1)

Recruited to MERT $(n=7)$

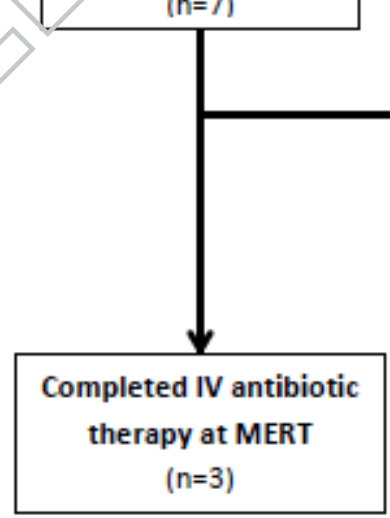


Table 1. Demographics of patients needing IV antibiotics and SUD treatment, comparing MERT and non-MERT individuals by antibiotic treatment location

\begin{tabular}{|c|c|c|c|c|c|}
\hline & $\begin{array}{l}\text { All } \\
(n=45)\end{array}$ & $\begin{array}{l}\text { Hospital } \\
(n=24)\end{array}$ & $\begin{array}{l}\text { MERT } \\
(n=7)\end{array}$ & $\begin{array}{l}\text { SNF } \\
(n=11)\end{array}$ & $\begin{array}{l}\text { Home } \\
(n=3)\end{array}$ \\
\hline $\begin{array}{l}\text { Mean age in years } \\
\text { (range) }\end{array}$ & 39 (21-69) & 37 (21-69) & $38(28-57)$ & $43(25-55)$ & $36(27-46)$ \\
\hline $\begin{array}{l}\text { Female Gender } n \\
(\%)\end{array}$ & $20(44 \%)$ & $12(46 \%)$ & $2(29 \%)$ & $4(36 \%)$ & $2(67 \%)$ \\
\hline $\begin{array}{l}\text { Non-Hispanic } \\
\text { White } n(\%)\end{array}$ & $38(84 \%)$ & $20(83 \%)$ & $6(86 \%)$ & $10(91 \%)$ & \\
\hline Any Insurance (\%) & 45 (100\%) & & & & \\
\hline Oregon & $33(73 \%)$ & 19 (79\%) & $4(57 \%)$ & $8(73 \%)$ & \\
\hline $\begin{array}{l}\text { Medicaid } \\
\text { Insecure housing } n \\
(\%)\end{array}$ & $23(51 \%)$ & $17(71 \%)$ & $2(29 \%)$ & $\%)$ & \\
\hline $\begin{array}{l}\text { Substance Use } \\
\text { Disorder }(\%)^{*}\end{array}$ & & & & & \\
\hline Opioid & $\begin{array}{l}37(82 \%) \\
27(60 \%)\end{array}$ & $\begin{array}{l}23(96 \%) \\
17(71 \%)\end{array}$ & $\begin{array}{l}7(100 \%) \\
2(29 \%)\end{array}$ & & $\begin{array}{l}2(67 \%) \\
1(33 \%)\end{array}$ \\
\hline $\begin{array}{l}\text { Methamphetamine } \\
\text { Cocaine }\end{array}$ & $5(11 \%)$ & $3(16 \%)$ & & & $1(33 \%)$ \\
\hline Alcohol & $5(11 \%)$ & $2(8 \%)$ & 0 & $3(27 \%)$ & 0 \\
\hline Benzodiazepine & $3(7 \%)$ & 0 & $2(23 \%)$ & $1(9 \%)$ & 0 \\
\hline $\begin{array}{l}\text { Any Severe SUD } \\
(\%)^{*}\end{array}$ & $38(84 \%)$ & $23(96 \%)$ & & $8(73 \%)$ & $1(33 \%)$ \\
\hline $\begin{array}{l}\text { Polysubstance use } \\
\text { (\%) }\end{array}$ & $28(62 \%)$ & $18(75 \%)$ & & $4(36 \%)$ & $1(33 \%)$ \\
\hline Infection site & & & & & \\
\hline Endocarditis & $16(36 \%)$ & $11(16 \%)$ & $1(14 \%)$ & $4(36 \%)$ & 0 \\
\hline Osteomyelitis & $14(31 \%)$ & $6(25 \%)$ & $3(43 \%)$ & $4(36 \%)$ & $1(33 \%)$ \\
\hline Bacteremia & $9(20 \%)$ & $6(25 \%)$ & 0 & $1(9 \%)$ & $2(67 \%)$ \\
\hline Other & $6(13 \%)$ & $1(4 \%)$ & $3(43 \%)$ & $2(18 \%)$ & 0 \\
\hline
\end{tabular}

*Defined by Diagnostic and Stacistical Manual of Mental Disorders fifth edition (DSM-5) criteria as assessed by IMPACT clinicians 
Table 2. Antibiotic completion rates and out-of-hospital IV antibiotic days by planned antibiotic treatment location*

\begin{tabular}{|c|c|c|c|c|c|}
\hline & $\begin{array}{c}\text { All } \\
(n=45)\end{array}$ & $\begin{array}{l}\text { Hospital } \\
(n=24)\end{array}$ & $\begin{array}{l}\text { MERT } \\
(n=7)\end{array}$ & $\begin{array}{c}\text { SNF } \\
(n=11)\end{array}$ & $\begin{array}{l}\text { Home } \\
(n=3)\end{array}$ \\
\hline $\begin{array}{l}\text { Completed recommended IV } \\
\text { antibiotic course, \% (n) }\end{array}$ & $44 \%(20)$ & $42 \%(11)$ & $43 \%(3)$ & $64 \%(7)$ & $33 \%(1)$ \\
\hline $\begin{array}{l}\text { Completed at least } 80 \% \text { of } \\
\text { recommended IV antibiotic course, } \\
\%(n)\end{array}$ & $64 \%(29)$ & $67 \%(16)$ & $43 \%(3)$ & $73 \%(8)$ & \\
\hline $\begin{array}{l}\text { Salvage therapy with oral } \\
\text { antibiotics, } \%(n)^{* *}\end{array}$ & $24 \%(11)$ & $21 \%(5)$ & $29 \%(2)$ & & $(2)$ \\
\hline $\begin{array}{l}\text { Total out-of-hospital IV antibiotic } \\
\text { days }\end{array}$ & 384 & 0 & & & 57 \\
\hline
\end{tabular}

*All participants initiated their course of IV antibiotics in the hospital. This table describes the intended location for completion of IV antibiotic treatment.

**Salvage therapy includes those who were transitioned from I to oral aritibiotics 